\title{
Simulation-Based Peer-Assisted Learning: Perceptions of Health Science Students
}

\author{
Muna Aljahany $\mathbb{D}^{1}$ \\ Haifaa Malaekah (D) ${ }^{2}$ \\ Hayat Alzahrani' \\ Fatimah Alhamadah ${ }^{3}$ \\ Wireen Leila Dator ${ }^{4}$ \\ 'Clinical Sciences Department, Faculty of \\ Medicine, Princess Nourah Bint \\ Abdulrahman University, Riyadh, Saudi \\ Arabia; ${ }^{2}$ Department of Surgery, Dr. \\ Sulaiman Alhabib Hospital, Altakhasussi, \\ Riyadh, Saudi Arabia; ${ }^{3}$ Department of \\ Surgery, King Abdullah bin Abdulaziz \\ University Hospital, Riyadh, Saudi Arabia; \\ ${ }^{4}$ Faculty of Nursing, Princess Nourah Bint \\ Abdulrahman University, Riyadh, Saudi \\ Arabia
}

\begin{abstract}
Objective: Since 2010, simulation-based learning has become increasingly popular as a well-recognized method of learning used by medical undergraduates in clinical settings. However, the relatively new concept of simulation-based peer-assisted learning has not yet been widely accepted, so it has not been well documented. Therefore, this study evaluated the perceived advantages of simulation-based peer-assisted learning among health professions students and interns and their acceptance of this new concept of learning from a student-instructor.
\end{abstract}

Methods: This was a pilot study conducted with 11 students in various health profession fields at Princess Nourah bint Abdulrahman University (PNU). The students were given a comprehensive lecture on simulation scenario development and were assigned to four separate interdisciplinary teams for a practical session on simulation scenario writing. Then, they each completed a questionnaire seeking their opinion concerning their experience and concept understanding.

Results: The results confirmed the advantages of interprofessional simulation-based peerassisted learning as it helped in understanding the process as perceived by the study participants. All students expressed their willingness and enthusiasm to use simulation as a technique for peer-assisted learning.

Conclusion: The study affirms the importance of developing student teachers' teaching skills at an institutional level. The future implementation of simulation-based peer-assisted learning is dependent on the students' awareness of the concept. By exploring a new dimension of medical education, the student teachers could expand their horizon of exposure to holistic case management and interactive learning and equip themselves with practical communication skills to excel in a real-world setting.

Keywords: peer-assisted learning, simulation-based learning, student teachers, interprofessional education, teaching skills

\section{Introduction}

Medical education has introduced countless teaching methods over the past decades to fill in the gaps and deal with issues in the teaching process. Many universities have adopted innovative and flexible educational methods, such as problem-based learning, puzzle-based learning, small group instruction, and team-based learning. Recently, some medical universities have adopted peer-assisted learning (PAL) and are considered among the most efficient educational strategies wherein students are actively involved in the teaching process. ${ }^{1}$ PAL was first introduced as an innovative teaching method in $1998 .^{1}$ It is defined as people from similar social groupings who are not professional teachers helping each other to learn and learning
Correspondence: Haifaa Malaekah

Princess Nourah Bint Abdulrahman

University, Airport Road, Riyadh, II564,

Saudi Arabia

Tel +966I I82387II

Email h_malaika@hotmail.com 
themselves by teaching. ${ }^{2-4}$ Since 2010 , it has gradually become a well-recognized method of learning used by medical undergraduates in preclinical and clinical settings. ${ }^{5,6}$

Recently, there has been an increased prevalence of using simulation-based scenarios in both student teaching and training. ${ }^{7}$ This will most likely have a significant and sustained effect on knowledge, skills acquisition, and retention. Moreover, it can help in producing downstream results in medical education. ${ }^{8}$ Peer-teaching is one of the most common PAL strategies, where tutor participation as an additional activity is voluntary and open to all students within the cohort. However, in some cases, peer tutors are known to be selected based on their academic performance. ${ }^{7}$ A systematic review by Rees et $\mathrm{al}^{9}$, found through meta-analysis that there is no significant difference in teaching outcomes in students taught by peers or faculty. Therefore, they recommend peer teaching as it helps in enhancing knowledge and teaching skills. ${ }^{9}$

Nunink and Thompson, ${ }^{10}$ who studied scenario-based learning program among final year medical students, posit that one of the unique benefits of PAL is that it enables students to effectively acquire the perspective of patients and colleagues from other medical disciplines. ${ }^{10}$ PAL has shown success in preclinical and clinical environments, enabling students to make judgments on a broader range of observed professional behavior compared to when their clinical supervisors only teach them. ${ }^{11}$ Students are likely to save time through collaboration and sharing knowledge rather than replicating the efforts of their peers. Qualities like self-directed learning skills, evaluative judgement, and the ability to partake in productive teamwork are developed through using PAL in clinical medical education. ${ }^{11}$ These qualities are necessary for becoming an effective and independent medical practitioner.

PAL continues to be an area of investigation among researchers interested in the development of medical education after simulation-based teaching by faculty, in comparison to simulation-based teaching by student teachers. ${ }^{12}$ However, previous studies have failed to explore the advantages of PAL among larger groups and its longterm impact on peer teaching. ${ }^{5,13}$ Students' involvement in the design process of the simulation scenario is believed to extend the potential of simulation as a learning method.

Though the effectiveness of PAL in medical education has been endorsed, there is a lack of qualitative data on the new simulation-based peer-assisted learning (SB-PAL) concept. ${ }^{14}$ It is important to understand students' perception and experiences of PAL, while considering the successful implementation of activities that encourage peer observation, feedback, discussion, and teaching in clinical education. There is a lack of evidence about formally organized PAL sessions; however, informal PAL can be witnessed in medical colleges. This highlights the need for exploring the utility of this method of learning in medical colleges to provide some strength in paving the way for the inclusion of PAL in the curriculum. Furthermore, at our university, student facilitators had not been formally trained in PAL teaching approaches and advantages, and it was realized from reading the literature that a workshop is needed to train them. The intention was for them to experience PAL first hand. Therefore, this study aimed to evaluate the acceptance of health science students of SB-PAL during the creation of simulation scenarios. Whereas, the objective of the study is to develop and implement a PAL workshop on simulation design and facilitation, specifically designed for interprofessional health science students who plan to assume roles as student teachers or lead interns in clinical settings.

\section{Materials and Methods Study Design and Setting}

It was a mixed-method survey study in which the included participants were students from PNU. The students were given a comprehensive lecture on simulation scenario development and were assigned to separate interdisciplinary teams for a practical session on simulation scenario writing. Then, they each completed a questionnaire seeking their opinion concerning their experience and concept understanding. The topics covered in the workshop included the students' course objectives over the five years, such as "work cooperatively with peers to achieve specified tasks," "understand the importance of teamwork and collaboration in caring for people with complex or chronic conditions", and "participate collaboratively." Moreover, the focus was on PAL outcomes rather than emphasizing the curriculum.

\section{Sampling and Recruitment}

Non-probability purposive sampling (based on their education, willingness and availability) was used to recruit 11 health science students from a population of 350 students. The small sample size was due to the study being a pilot study. An announcement about a limited-seat workshop on simulation scenario writing and the conduct of simulation sessions were sent to health science students, and the workshop attendees were invited to participate in the study. Participation in the 
study was restricted to PNU affiliated senior students or fresh graduates (ie, interns). Students at the clinical and internship level from four healthcare colleges (medicine, dentistry, pharmacy, and health and rehabilitation sciences) were included. Only students who agreed to participate in the research and signed consent were included and attended the workshop (11 students). At the end of the workshop, the subjects were asked to complete a written questionnaire.

\section{Study Tool}

The study tool included survey questions based on the research aims and analysis of the PAL literature. ${ }^{15,16}$ The item wording was drafted by a researcher based on the literature along with discussions with the research team. The survey was uploaded online on Survey Monkey. It remained available online for one month. The questionnaire used as the study tool consisted of two sections:

- Demographic details about the participants (2 questions)

- Participants' perception (3 open-ended questions)

\section{Study Procedure}

The workshop took place at the simulation and skills development centre at PNU. The students were provided with a workshop about designing and implementing simulation activity (Table 1). During the workshop, one facilitator served as the workshop auditor and was responsible for observing and manually recording participants' comments with respect to their experience and concept understanding. The comments were reported in the form of the participants' phrases. The auditor did not participate in delivering any educational material or in facilitating the group-based activities. Before completing the questionnaire, the participants were informed of the auditor's role, given a comprehensive lecture on scenario development, and assigned to 4 interdisciplinary workgroups. Each group had to have at least one member from each of the health sciences colleges at PNU (ie, college of medicine, college of dentistry, college of pharmacy, and college of health and rehabilitation sciences).

\section{Data Analysis}

A mixed-method analysis was conducted, and quantitative data were presented as frequencies. Further, a descriptive analysis was performed to assess the distribution of concept acceptability. Subtractive abstraction was used on the information collected from the open-ended questions and during the session auditing to build a panoramic
Table I The Workshop's Structured Activities

\begin{tabular}{|l|}
\hline Activity \\
\hline Welcome and overview of the workshop and introducing the team \\
\hline Pre-workshop evaluation \\
\hline Simulation terminology \\
\hline Target audiences and needs assessment \\
\hline Practice \\
\hline Learning objectives \\
\hline Practice \\
\hline Simulation modalities \\
\hline Practice \\
\hline Coffee break \\
\hline Case description and case environment \\
\hline Practice \\
\hline Staging needs: equipment, moulage, staff needed, adjunct \\
\hline Practice \\
\hline The script scenario framework and staging \\
\hline Practice \\
\hline Types of debriefing \\
\hline Practice \\
\hline Case presentation by students: each group 5 minutes \\
\hline Post-workshop evaluation \\
\hline
\end{tabular}

understanding and draw a potential conceptual framework for future concept implementation.

\section{Ethics Approval}

A pilot study was conducted after obtaining appropriate authorization from PNU through the Institutional Review Board.

\section{Results}

There were 11 participants. Their ages range between 21 and 25 years. All of them were females. There were four from the college of medicine, one from the college of dentistry, four from the college of pharmacy, and two from the college of health and rehabilitation sciences. All participants completed the online questionnaire and submitted their comments on the advantages, challenges, and perceptions regarding their experience with SB-PAL. Table 2 
Table 2 Survey Questionnaire and Participant Responses

\begin{tabular}{|c|c|c|c|c|}
\hline Questions & $\begin{array}{l}\text { Number of } \\
\text { Responders }\end{array}$ & $\begin{array}{l}\text { Agree } \\
(\%)\end{array}$ & $\begin{array}{l}\text { Neutral } \\
\text { (\%) }\end{array}$ & $\begin{array}{l}\text { Disagree } \\
(\%)\end{array}$ \\
\hline QI) SB-PAL is a good idea to facilitate student learning. & II & $100 \%$ & $0 \%$ & $0 \%$ \\
\hline Q2) SB-PAL will develop my teaching skills. & 11 & $95 \%$ & $4.50 \%$ & $0 \%$ \\
\hline Q3) The idea of being instructor in SB-PAL excites me. & $\mathrm{II}$ & $95 \%$ & $4.50 \%$ & $0 \%$ \\
\hline $\begin{array}{l}\text { Q4) As a student instructor in SB-PAL, I will learn how to design a teaching plan and } \\
\text { simulation scenario. }\end{array}$ & $\mathrm{II}$ & $95 \%$ & $4.50 \%$ & $0 \%$ \\
\hline Q5) With SB-PAL, I will learn the process of facilitating a simulation. & $\mathrm{II}$ & $95 \%$ & $0 \%$ & $4.50 \%$ \\
\hline $\begin{array}{l}\text { Q6) With SB-PAL, I will know how to put a real-life situation in a safe environment, } \\
\text { such as a simulation }\end{array}$ & 11 & $95 \%$ & $4.50 \%$ & $0 \%$ \\
\hline $\begin{array}{l}\text { Q7) As a student instructor in SB-PAL, I need to know how to evaluate the } \\
\text { responses of student learners. }\end{array}$ & II & $86.3 \%$ & $13.6 \%$ & $0 \%$ \\
\hline $\begin{array}{l}\text { Q8) As a student instructor, I can develop my critical thinking and decision-making } \\
\text { skills. }\end{array}$ & 11 & $100 \%$ & $0 \%$ & $0 \%$ \\
\hline Q9) I am interested to be a student instructor in SB-PAL. & II & $95 \%$ & $4.50 \%$ & $0 \%$ \\
\hline QI0) I have enough time to be involved as instructor in SB-PAL. & II & $90.9 \%$ & $4.50 \%$ & $4.50 \%$ \\
\hline $\begin{array}{l}\text { QI0) I need to make more effort to learn about the concepts before I can be an } \\
\text { instructor in SB-PAL. }\end{array}$ & $\mathrm{II}$ & $100 \%$ & $0 \%$ & $0 \%$ \\
\hline $\begin{array}{l}\text { Q12) I believe the other students will be interested to learn through student- } \\
\text { instructors in SB-PAL. }\end{array}$ & $\mathrm{II}$ & $95 \%$ & $4.50 \%$ & $0 \%$ \\
\hline QI3) SB-PAL is a better way of knowledge retention for me as a student instructor. & II & $95 \%$ & $0 \%$ & $4.50 \%$ \\
\hline QI4) SB-PAL should be encouraged among the students. & II & $95 \%$ & $0 \%$ & $4.50 \%$ \\
\hline
\end{tabular}

summarizes the participants' responses to the quantitative part of the survey. The majority of the participants provided positive responses and a positive approach to SB-PAL.

Tables 3-5 represent the participants' responses in their own words to the open-ended, qualitative part of the questionnaire. Regarding advantages, majority of the participants reported SB-PAL to be a new experience and beneficial for their learning (Table 3). Whereas participants reported lack or time to be a barrier along with complain of not sharing knowledge, while some said they found no difficulties with SB-PAL (Table 4). Similarly, majority had a positive perception regarding SB-PAL and reported it provided good communication between the student tutor and their peers (Table 5).

The challenges of interprofessional SB-PAL were factors related to either the participants or the workshop design scheme. The participant-related factors were primarily centered on the lack of previous experience, difficulties in identifying patients' needs, and academic schedule congestion. The factors related to workshop design were the condensed course schedule, the fact that the attendees were predominantly medical students who shifted the topics to focus more on medically related topics, and difficulty in extending and sharing information. This workshop was the first of its kind designed in Saudi Arabia. However, future implementation of SB-PAL is dependent on the awareness of students and mentors of the concept. Their eagerness to participate in and integrate this education scheme into the ongoing workshops is highly important. The participants support future workshops as they integrate SB-PAL into their curriculum due to the freedom to exchange thoughts and knowledge. Further, it eliminates the pressure that comes along with interacting with seniors.

\section{Discussion}

This study evaluated the perceived advantages of SB-PAL among students and their acceptance of this new concept. This session was confirmed to be a good source of information that could offer opportunities to the students to 
Table 3 Advantages of Simulation-Based Peer-Assisted Learning

\section{What Do You Think are The Advantages of Simulation- Based Peer-Assisted Learning?}

"It is a new thing to me to learn and it lets me think on the basis of whether something can be applied in real life."

"I-knowing more about the scenario making ... 2-good use of time and learning new things as exciting as this topic 3-can get this course free of cost at the perfect time."

"This is my first time to know about the hard work they do in the simulation center."

"It's more beneficial in practice than standard learning strategy."

"I learn from it."

"Excellent instructors."

"We got good information, the instructors are so sweet."

"It's a good experience as a student, clarify things and making them easier."

"It can improve my skills in making quick decisions and it makes me so excited."

"To learn about technologies and improve practice for all healthcare students."

"It would increase my knowledge and area of learning and increase my way of communication, it's really simulating reality."

explore a new dimension of medical education. Further, it helped the students to establish a better understanding of addressed topics, improve their clinical skills, expand their horizon of exposure to holistic case management, improve their information retention with interactive learning, and equip them with the communication skills necessary to excel in a real-life setting. This study supports the notion that student-led teaching is highly advantageous. Through such activities, students can approach their colleagues and explain things by themselves, which could, in effect, also deepen the student instructor's understanding of a topic. Moreover, the study showed that the participants learned new skills, which is necessary to excel in a real-life setting through teamwork and professionalism.

The students were keen on acquiring additional skills that would help them in developing a professional identity. In line with this, Al-Elq ${ }^{17}$ found that student teachers were given the opportunity to practice and improve their medical knowledge along with their teaching skills. Another study by Yamamoto et $\mathrm{al}^{16}$ stated that it is important to understand that students consider teaching skills as
Table 4 Challenges of Simulation-Based Peer-Assisted Learning

What Do You Think are the Challenges or Difficulties for a Student Instructor in Simulation-Based Peer-Assisted Learning?

"It's for me is the time."

"I-the workshop is designed for medicine students most of the time, we are not on the same page as other, 2- the girls in the same group not sharing information and not choosing a topic that can include us all (different specialty)."

"With simulation directors I think there will be no difficulties, thank you."

"It takes time to prepare an excellent scenario."

“None.”

"It should be done in at least two days, we would benefit more."

"No."

"It's difficult to be a student instructor, I should learn how to identify what the patient needs."

"Yes, but as a part of other professional instructors."

"The time management for studying and activity, lack of practice and professionalism in this field."

Table 5 Perceptions of Simulation-Based Peer-Assisted Learning

Do You Think That Students Would Like to Learn from a Student-Instructor? And Why?

"Yes, because of the level of communication and comfortable to take information from a young new graduated student."

"Yes, I do, but as I said they must learn a few things first and choose good topics, so the experience will be as good as possible."

"Yes, and I will inform all my friends."

"Yes, they look at her as a colleague and she passed over these situations and know the obstacles they faced."

"Yes."

"Yes, it will be less stress."

"Yes, more understandable, more comfortable for the students to deal with a student."

"Yes, because your scenario will be famous, and many students will do it."

"Yes, I think so, it may be because they can talk comfortably with no limitations." 
requisite graduate competencies. The student teachers understood the student learners' level of knowledge because of the close relationship they have with each other as learners. Consequently, this allowed for individual solutions for various difficulties. In this aspect, a few of the previous studies suggested that the experiences of student teachers are linked to the concept of cognitive and social congruence in peer teaching skills in laboratory settings.

Further, a study conducted by Burgess et $\mathrm{al}^{18}$ demonstrated the significance of a congruent relationship between student teachers and learners, as social congruence and successful group learning outcomes are somewhat associated with each other. This study discovered that the primary reason behind the students' support for PAL was the freedom they have in exchanging knowledge and thoughts. Concurrently, a few of the previous studies showed the effectiveness of PAL in comparison to superior workshops taught by the faculty staff., ${ }^{5,19,20}$ Therefore, PAL can be considered as an effective teaching method, as it reinforces the idea of social and cognitive congruence.

The students felt free and relaxed to share their expertise, which would ultimately improve their procedural skills and factual knowledge. A similar study conducted by Ten Cate and Durning ${ }^{21}$ found that students were more likely to have better knowledge retention when students taught other students in a relevant field. Student teachers' motivation could increase due to the financial incentives along with the prospect of gaining professional experience that could lead to better career opportunities. Moreover, student teachers are more likely to retain concepts that they teach and often spend more time preparing for the topics that they are expected to teach. On the other hand, student learners become more engaged in active learning and are at ease to ask questions and further clarifications from fellow students. This means that a PAL environment reduces the psychological pressure and stress among students through group discussions that further improve their learning. Students expressed motivation and enthusiasm toward the concept of being simulation instructors and using simulation to educate their peers.

This study has several strengths, which include the involvement of a diverse range of students with different specializations. The mixed methodological approach (quantitative and qualitative analysis) enables us to describe the students' experience from all aspects. In addition, it was the first study on the perception of PAL on an interprofessional education group done in the region.

However, the results of the study are limited, as only a few participants were selected for conducting quantitative descriptive analysis. Based on a review of previous literature, skilled researchers developed a questionnaire that maximized validity and minimized the possibility of bias. In addition, as the study took place at a women's university, there were no male participants. This could affect the perception as well as the outcome of the results. Moreover, the study did not obtain feedback from the learners; instead, the study only focused on the experiences and impressions of the student teachers.

The study recommends and suggests the importance of developing teaching skills among students at an institutional level. The SB-PAL was a positive and novel approach for many that helped in their learning. Therefore, incorporating it in the curriculum as an optional learning method can help in their curriculum learning. Future studies need to focus on the identification, selection, and training of competent student teachers.

\section{Conclusion}

This study was able to gain deep insight into the experiences of student teachers with respect to SB-PAL. It helped the faculty members to learn more about the motivations of student teachers to teach. The results confirmed the significance of the theoretical concepts of social and cognitive congruence among the student teachers. Their enthusiasm for teaching increased as a result of social and cognitive congruence, which equally increased the level of interaction with learners. This is considered as one of the major reasons behind the student teachers' personal commitment.

\section{Acknowledgment}

The authors are very thankful to all the associated personnel that contributed to this research. Special thanks to Dr. Weam Banjar for her help and contribution.

\section{Funding}

This research was funded by the Deanship of Scientific Research at Princess Nourah Bint Abdulrahman University, Riyadh, Saudi Arabia, through the Fast-track Research Funding Program. 


\section{Disclosure}

The authors declare no conflicts of interest.

\section{References}

1. Abedini M, Mortazavi F, Javadinia SA, Moonaghi HK. A new teaching approach in basic sciences: peer assisted learning. Procedia Soc Behav Sci. 2013;83:39-43. doi:10.1016/j.sbspro.2013.06.008

2. Burgess A, McGregor D, Mellis C. Medical students as peer tutors: a systematic review. BMC Med Educ. 2014;14:115. doi:10.1186 1472-6920-14-115

3. Habib SH, Malik MO, Fatima S, Shah I. Evaluation of peer assisted learning in evidence based medicine course: a pilot study at university of glasgow. J Ayub Med Coll Abbottabad. 2017;29:662-666. doi:10.3386/w23195

4. Jauregui J, Bright S, Strote J, Shandro J. A novel approach to medical student peer-assisted learning through case-based simulations. West J Emerg Med. 2018;19:193. doi:10.5811/westjem.2017.10.35319

5. de Silva NL, Parththipan B, Rodrigo C, Constantine G, Fernando SD, Rajapakse S. Peer assisted learning among Sri Lankan medical undergraduates: a cross sectional study. BMC Res Notes. 2017;10:595. doi:10.1186/s13104-017-2920-2

6. Shah I, Mahboob U, Shah S. Effectiveness of horizontal peer-assisted learning in physical examination performance. J Ayub Med Coll Abbottabad. 2017;29:559-565. doi:10.2147/amep.s14383

7. Shiner N. Is there a role for simulation based education within conventional diagnostic radiography? A literature review. Radiography. 2018;24:262-271. doi:10.1016/j.radi.2018.01.006

8. McGaghie WC, Issenberg SB, Barsuk JH, Wayne DB. A critical review of simulation-based mastery learning with translational outcomes. Med Educ. 2014;48:375-385. doi:10.1186/s13104-0172920-2

9. Rees EL, Quinn PJ, Davies B, Fotheringham V. How does peer teaching compare to faculty teaching? A systematic review and meta-analysis. Med Teache. 2016;38(8):829-837. doi:10.3109/ 0142159X.2015.1112888

10. Nunnink L, Thompson A. Peer-assisted learning in scenario-based simulation. Med Educ. 2018;52:557. doi:10.1111/medu.13563
11. Tai JH, Haines TP, Canny BJ, Molloy EK. A study of medical students' peer learning on clinical placements: what they have taught themselves to do. J Peer Learn. 2014;7:57-80.

12. Walsh R. Lifestyle and mental health. Am Psychol. 2011;66:579. doi:10.1037/a0021769

13. Hodgson Y, Bearman M, Schneider-Kolsky M. Lessons learned in implementing peer-assisted learning. Int J Innov Sci Math Educ. 2012;20(3):19-30.

14. Guraya SY, Abdalla ME. Determining the effectiveness of peer-assisted learning in medical education: a systemic review and meta-analysis. J Taibah Univ Medical Sci. 2020;15(3):177-184.

15. Weyrich P, Schrauth M, Kraus B, et al. Undergraduate technical skills training guided by student tutors-analysis of tutors' attitudes, tutees' acceptance and learning progress in an innovative teaching model. BMC Med Educ. 2008;8:18.

16. Yamamoto A, Obika M, Mandai Y, et al. Effects on postgraduate-year-I residents of simulation-based learning compared to traditional lecture-style education led by postgraduate-year-II residents: a pilot study. BMC Med Educ. 2019;19:87. doi:10.1186/ s12909-019-1509-y

17. Al-Elq AH. Simulation-based medical teaching and learning. J Family Community Med. 2010;17(1):35-40. doi:10.4103/13191683.68787

18. Burgess A, Dornan T, Clarke AJ, Menezes A, Mellis C. Peer tutoring in a medical school: perceptions of tutors and tutees. BMC Med Educ. 2016;16:85. doi:10.1186/s12909-016-0589-1

19. Nyquist JG. Educating physicians: a call for reform of medical school and residency. $J$ Chiropr Educ. 2011;25:193. doi:10.1001/ jama.2010.1351

20. Lockspeiser TM, O’Sullivan P, Teherani A, Muller J. Understanding the experience of being taught by peers: the value of social and cognitive congruence. Adv Health Sci Educ. 2008;13:361-372. doi:10.1007/s10459-006-9049-8

21. Ten Cate O, Durning S. Peer teaching in medical education: twelve reasons to move from theory to practice. Med Teach. 2007;29:591-599. doi:10.1080/01421590701606799
Advances in Medical Education and Practice

\section{Publish your work in this journal}

Advances in Medical Education and Practice is an international, peerreviewed, open access journal that aims to present and publish research on Medical Education covering medical, dental, nursing and allied health care professional education. The journal covers undergraduate education, postgraduate training and continuing medical education including emerging trends and innovative models linking education, research, and health care services. The manuscript management system is completely online and includes a very quick and fair peer-review system. Visit http://www.dovepress.com/testimonials.php to read real quotes from published authors. 